\title{
To Study the Outcome of Cataract Surgery in a Rural Indian Population Which Primarily Depends on Camps and NGOs for a Free Cataract Surgery
}

\author{
Bodhraj Dhawann ${ }^{1}$, Vaishali Bodhraj Dhawan² \\ ${ }^{1}$ Department of Ophthalmology, NKP Salve Institute of Medical Sciences, Nagpur, Maharashtra, India. ${ }^{2}$ Department \\ of Radiology, Mahatma Gandhi Institute of Medical Sciences, Sevagram, Wardha, Maharashtra, India.
}

\section{ABSTRACT}

\section{BACKGROUND}

The present study was conducted as a rapid assessment of avoidable blindness survey by cluster sampling, aimed primarily to assess the outcome of cataract surgery in a rural Indian population.

\section{METHODS}

An Observational Point Prevalence study including 407 pseudophakic eyes of 382 subjects, screened through Survey across District in Rural Wardha and admitted in the eye ward of a Rural Tertiary Care Teaching Centre, who gave informed consent were included in this study. History of cataract surgery (time, place, cost and provision of glasses), diabetes mellitus, past history of laser capsulotomy was recorded. Visual acuity and thorough ocular examination including grading of PCO were done. Ocular findings were recorded on pre-tested proforma.

\section{RESULTS}

Prevalence of PCO among the pseudophakic eyes was 31.4\%. Mean age of study population was $68.1 \pm 8.3$ years (range 14-86 years). Rates of PCO are noted to be minimum (21.4\%) in the age group 55 - 59 years and maximum $(36.1 \%)$ in the age group 75 - 79 years. Mean duration since surgery in eyes with PCO among the total 407 pseudophakic eyes included in the study was $27.9 \pm 23.7$ months (range 1 - 120 months), $14.9 \%$ eyes developed visually significant PCO in $<12$ months since surgery. Prevalence of PCO ranged from $14.9 \%$ in $<12$ months since surgery to $32.0 \%$ at $<60$ months since surgery $(\chi 2=23.99, \mathrm{p}<0.05)$. In the study group which included 5 (23.9\%) eyes with a Foldable IOL, developed PCO as compared to 133 (34.5\%) in the eyes implanted with PMMA IOL. Prevalence of PCO was higher in PMMA IOL. In the study group, 45 (59.2\%) eyes with a Decentered IOL had PCO as compared to 93 (28.1\%) eyes within the Bag placed IOL group. There was a higher prevalence of visually significant PCO in eyes with decentered IOL, as compared to eyes within the Bag IOL placement. $\left(\chi^{2}=26.71, D F=1, p=0.00000\right)$. Out of 407 pseudophakic eyes included in the study, history of diabetes was noted in 14 persons, of whom 14 (3.4\%) pseudophakic eyes were included in this study and 9 (64.3\%) of these developed PCO. The prevalence of PCO was significantly higher among diabetic patients $\left(\chi^{2}=4.65\right.$, $\mathrm{p}<0.05)$. The presence of uveitis in pseudophakic eyes was significantly related to higher PCO rates as compared to pseudophakic eyes without uveitis. $\left(\chi^{2}=24.68, \mathrm{DF}=1\right.$, $\mathrm{p}=0.000001$ ).

\section{CONCLUSIONS}

Visually Significant PCO is seen in $1 / 3^{\text {rd }}$ of eyes following cataract surgery. Duration since cataract surgery is a major factor influencing its genesis. IOL material, cataract surgery type, and IOL position are also important factors. Role of diabetes and uveitis needs to be studied further.

\section{KEY WORDS}

Posterior Capsule Opacification, Pseudophakia, Cataract Surgery
Corresponding Author:

Bodhraj Dhawan,

\#30, H. B. Estate,

Sonegaon, Nagpur-440025,

Maharashtra, India.

E-mail: bodhrajdhawan@gmail.com

DOI: $10.14260 / j e m d s / 2020 / 588$

How to Cite This Article:

Dhawan B, Dhawan VB. To study the outcome of cataract surgery in a rural Indian population which primarily depends on camps and NGOs for a free cataract surgery. $J$ Evolution Med Dent Sci 2020;9(37):2704-2709, DOI: $10.14260 / j e m d s / 2020 / 588$

Submission 14-04-2020,

Peer Review 06-08-2020,

Acceptance 11-08-2020,

Published 14-09-2020.

Copyright (C) 2020 JEMDS. This is an open access article distributed under Creative Commons Attribution License [Attribution 4.0 International (CC BY 4.0)] 


\section{BACKGROUND}

Posterior Capsule Opacification (PCO) is the prime deleterious consequence of cataract surgery. PCO occurs $30 \%-50 \%$ of times following cataract surgery during first three to five years. ${ }^{1}$ PCO is the commonest cause of blindness \& visual impairment in pseudophakic eyes which attained normal/near normal vision after surgery. This has led to increasing numbers of "Pseudophakic Blind" eyes with increasing practice of IOL implantation surgery than before. This is comparable to "aphakic blindness" which was common after old non IOL surgeries in cases not having received required aphakic correction. PCO thus has important implications in the developing world, where it may increasingly become a significant cause of treatable blindness. Several surgery related factors including hydrodissection enhanced cortical clean up, in the bag fixation of IOL \& capsulorhexis edge on IOL surface are known to affect development of PCO. Among the IOL related factors biocompatibility, maximal Axial IOL optic-posterior capsule contact, design \& material are of prime importance in proliferation of $\mathrm{PCO}^{2}$ Role of certain systemic factors like Diabetes Mellitus \& Rheumatoid arthritis in development of PCO is less proven. ${ }^{3}$

\section{METHODS}

All the patients admitted in the eye ward who had pseudophakia in the either eye and who gave informed consent were included in this study. History of cataract surgery (time, place, cost and provision of glasses), diabetic mellitus, past history of laser capsulotomy was recorded. Visual acuity was assessed with the help of Snellen's chart and refraction was done. Torch light and Slit lamp examination was done to assess ocular findings in anterior segment, and to assess the lens status. Grading of Posterior Capsular Opacification was done on slit lamp examination as per Sellman and Lindstrom grading of fibrosis and Elschnig pearl formation as follows. ${ }^{4}$ Fundus Examination was performed with Direct and Indirect Ophthalmoscope after dilating the pupil. Digital imaging was done for all patients to document the findings.

Intraocular pressure was recorded by Applanation Tonometer. In patients with hazy media B-Scan Ultrasonography was done. (as and when required) Ocular findings were recorded on pre-tested proforma. Patients with PCO grade II and or above with vision $<6 / 18$ \& those with obscured view of fundus were advised Nd-YAG Laser Capsulotomy.

\section{RESULTS}

During the study period 392 persons who had pseudophakia in one or both eyes and who were admitted in the eye ward and gave consent to be part of the study were evaluated as per study design.

\section{Age and Sex Distribution}

Out of 392 persons evaluated 214 (54.6\%) were males and $178(45.4 \%)$ were females. Mean age of study population was $68.1+8.3$ years (range 14-86 years). Majority of the persons $(230,58.6 \%)$ were in the age group $65-74$ years. Mean age of males was $68.4+7.6$ years (range $26-86$ years) and for females it was 67.7+9.1 years (range 14-84 years).

\section{Visual Status of Study Population}

Out of 392 persons included in this study 126 (32.1\%) had Visual Impairment, 11 (2.8\%) had Severe Visual Impairment and $26(6.6 \%)$ were suffering from Blindness as per WHO criteria. Of the 784 eyes included in this study, presenting visual acuity was normal/near normal in 46 (5.9\%) eyes, 345 (44\%) eyes had visual impairment, severe visual impairment was present in $123(15.7 \%)$ eyes and 270 (34.4\%) eyes were blind including 7 (0.9\%) eyes with visual acuity of PL negative. Based on Best Corrected Visual Acuity, 238 eyes had normal/near normal vision. 231 (29.5\%) eyes had visual impairment, 64 (8.2\%) eyes had severe visual impairment and $251(40 \%)$ eyes were blind including $7(0.9 \%)$ eyes with a visual acuity of PL negative.

\section{Lens Status}

Out of 392 persons included in this study 10 (2.5\%) had pseudophakia in both eyes and 387 (95.1\%) had unilateral pseudophakia. Out of the 784 eyes 407 (52.0\%) eyes had Pseudophakia and $372(47.4 \%)$ eyes had Cataract. In 5 (0.6\%) eyes, lens status could not be determined because of absent globe, phthisis bulbi or hazy media.

\section{Distribution of Place of Surgery in Pseudophakic Eyes}

Out of a total 407 operated eyes $49(12.0 \%)$ eyes were operated at Government Hospital and 275 (67.6\%) eyes were operated at NGO Hospital. 49 (12\%) of the eyes were operated at Private Hospital and 34 (8.4\%) eyes were operated in improvised eye camps.

\section{Distribution of Time Since Surgery in Pseudophakic Eyes} Out of 407 operated eyes, 161 (39.6\%) eyes were operated within last 12 months, 101 (24.8\%) were operated between 13-24 months. Only 20 (4.9\%) eyes were operated between 5 10 years.

\section{Distribution of Cost of Surgery in Pseudophakic Eyes}

Out of 407 operated eyes 337 (82.8\%) were operated Camp free and $70(17.2 \%)$ were operated at paid centers.

\section{Visual Status of Pseudophakic Eyes}

(Table No. 1) Out of 407 pseudophakic eyes majority (277, $68.0 \%$ ) had presenting visual acuity $<6 / 18->6 / 60$, only 38 (9.3\%) had presenting visual acuity $>6 / 18$ with available glass. Presenting visual acuity $<6 / 60$ was noted in $92(22.6 \%)$ eyes including $3(0.7 \%)$ eyes with visual acuity of PL negative. After refraction Best Corrected Visual Acuity of $>6 / 18$ was noted in $221(54.3 \%)$ eyes and 124 (30.5\%) eyes had visual 
acuity $<6 / 18->6 / 60$. Best Corrected Visual Acuity $<6 / 60$ was noted in $62(15.2 \%)$ eyes including $3(0.7 \%)$ eyes with visual acuity of PL negative.

\section{Distribution of Posterior Capsular Opacification (PCO)} Out of 407 pseudophakic eyes were included in this study only $9(2.2 \%)$ had undergone laser capsulotomy in past. Out of remaining 398 eyes 350 had capsular opacity of any grade. Out of total 350 eyes with pseudophakia with PCO, 222 (54.5\%) had PCO Grade I. Grade II PCO was noted in 88 (21.6) eyes, grade III and grade IV PCO was noted in 34 (8.4) and 6 (1.5) of the pseudophakic eyes respectively. Clear capsule was noted in $48(11.8 \%)$ eyes.

\section{Distribution of Best Corrected Visual Acuity and Grade of PCO}

Out of 221 eyes with grade I PCO majority $(145,65.6 \%)$ had normal/near normal Vision and 50 (22.6\%) had visual impairment whereas $26(11.7 \%)$ were blind. Out of 89 eyes with grade II PCO majority $(50,56.2 \%)$ had visual impairment. Out of 34 eyes with grade III PCO 18 (52.9\%) had visual impairment whereas 12 (35.3\%) were blind. Out of total 6 eyes with grade IV PCO, all (100\%) were blind.

Distribution of Time Since Surgery and Grade of PCO (Table No. 2, Figure 1) Out of all pseudophakic eyes operated in $<12$ months $24(14.9 \%)$ had significant PCO. Prevalence of significant PCO was noted to have an increasing trend through $<24$ months, $<36$ months, $<48$ months and $<60$ months to 55 (21.0\%), 81 (25.4\%), 86 (25.5\%) and 124 (32.0\%). Prevalence of significant PCO was noted to increase with increasing time since surgery.

\section{Distribution of Sex and Grade of PCO in Pseudophakic Eyes}

Out of 407 pseudophakic eyes included in this study, 225 $(55.3 \%)$ eyes belonged to male persons out of which 75 (33.4\%) developed PCO >grade I. Out of 182 (44.7\%) eyes belonging to female persons, $63(34.6 \%)$ developed PCO > grade I. Prevalence of significant PCO showed no significant different between sexes.

\section{Distribution of Age \& Grade of PCO}

Out of 407 pseudophakic eyes 17 (4.2\%) belonged to persons aged $<50$ years of which 6 (35.3\%) developed PCO $>$ Grade I. Prevalence of PCO >Grade I for age groups 50-54, 55-59, 60$64,65-69,70-74,75-79$ and $80-85$ years was 2 (33.4\%), 3 (21.4\%), 17 (35.4\%), 34 (32.7\%), 45 (34.4\%), 26 (36.1\%) and $5(33.4 \%)$ respectively.

\section{Distribution of Type of Surgery \& Grade of PCO}

Of the 407 operated eyes 110 (27\%) were operated by Conventional ECCE + IOL out of which 57 (51.8\%) eyes developed PCO more than grade I. 297 (73.0\%) eyes were operated by SICS / PHACO + IOL out of which 81 (27.3\%) develop PCO > Grade I. Prevalence of significant PCO was higher in eyes operated by conventional ECCE + IOL technique as compare to SICS / PHACO + IOL.

\section{Distribution of Type of IOL and Grade of PCO (Figure 2)}

The study population included 21 Foldable IOLs among all 407 pseudophakic eyes of which 5 (23.9\%) developed PCO > grade I. PMMA IOL was present in 386 eyes of which 133 (34.5\%) had PCO > grade I. Prevalence of significant PCO was lower in eyes having a foldable IOL.

\section{Distribution of Diabetic Status and Grade of PCO}

Out of 407 operated eyes, 14 (3.4\%) eyes were of diabetic persons of which 9 (64.3\%) developed PCO more than grade I. Among non-diabetic eyes prevalence of PCO was 129 (32.8\%). Prevalence of PCO was noted to be higher among diabetics.

\section{Distribution of IOL Position and Grade of PCO}

Out of 407 pseudophakic eyes decentered IOL was present in $76(18.7 \%)$ eyes of which $45(59.2 \%)$ had PCO more than Grade I. PCO rates for in the Bag group were 93 (28.1\%).

\section{Distribution of Uveitis and Grade of PCO}

Out of 407 operated eyes, uveitis was present in 184 (45.2\%) eyes out of which $86(46.7 \%)$ had PCO more than grade I. Out of 407 operated eyes Uveitis was absent 223 eyes (54.8\%) of which only 52 (23.3\%) eyes developed PCO more than grade I. Prevalence of PCO was noted to be higher in eyes with uveitis.

\begin{tabular}{|ccc|}
\hline Visual Status & $\begin{array}{c}\text { Presenting Visual } \\
\text { Acuity No. (\%) }\end{array}$ & $\begin{array}{c}\text { Best Corrected } \\
\text { Visual Acuity No. (\%) }\end{array}$ \\
$\geq 6 / 18$ & $38(9.3)$ & $221(54.3)$ \\
$<6 / 18-\geq 6 / 60$ & $277(68.0)$ & $124(30.5)$ \\
$<6 / 60-\geq 3 / 60$ & $35(8.6)$ & $15(3.7)$ \\
$<3 / 60-\mathrm{PL}+$ & $54(13.3)$ & $44(10.8)$ \\
PL Negative & $3(0.7)$ & $3(0.7)$ \\
\hline \multicolumn{2}{r}{ Table 1. Visual Status of Pseudophakic Eyes } \\
\hline$(\mathrm{n}=407)$ & \multicolumn{2}{c}{} \\
\hline
\end{tabular}

\begin{tabular}{|cccc|}
\hline $\begin{array}{c}\text { Time Since Surgery } \\
\text { (in months) }\end{array}$ & $\begin{array}{c}\text { No. Eyes } \\
\text { (\%) }\end{array}$ & $\begin{array}{c}\text { Grade 0/ } \\
\text { Grade I PCO }\end{array}$ & $\begin{array}{c}\text { Grade II, III, IV \& } \\
\text { Lasered PCO }\end{array}$ \\
$<12$ & $161(39.6)$ & $137(85.1)(50.9)$ & $24(14.9)(17.4)$ \\
$<24$ & $262(64.4)$ & $207(79.0)(77.0)$ & $55(21.0)(39.9)$ \\
$<36$ & $319(78.4)$ & $238(74.6)(88.5)$ & $81(25.4)(58.7)$ \\
$<48$ & $337(82.8)$ & $251(74.5)(93.3)$ & $86(25.5)(62.3)$ \\
$<60$ & $397(95.1)$ & $263(68.0)(97.8)$ & $124(32.0)(89.9)$ \\
$<120$ & $407(100)$ & $269(66.1)$ & $138(33.9)$ \\
\hline \multicolumn{4}{c}{ Table 2. Distribution of Diabetic Status, } \\
IOL Position, Uveitis and Grade of PCO
\end{tabular}

\section{DISCUSSION}

\section{Prevalence of Posterior Capsular Opacification}

In the present study the Prevalence of PCO among the pseudophakic eyes was $31.4 \%$. Various studies mention different rates of PCO depending on follow up period and other risk factors and grading modality results of which are consistent with the present study. ${ }^{5,6,7}$, and 8 

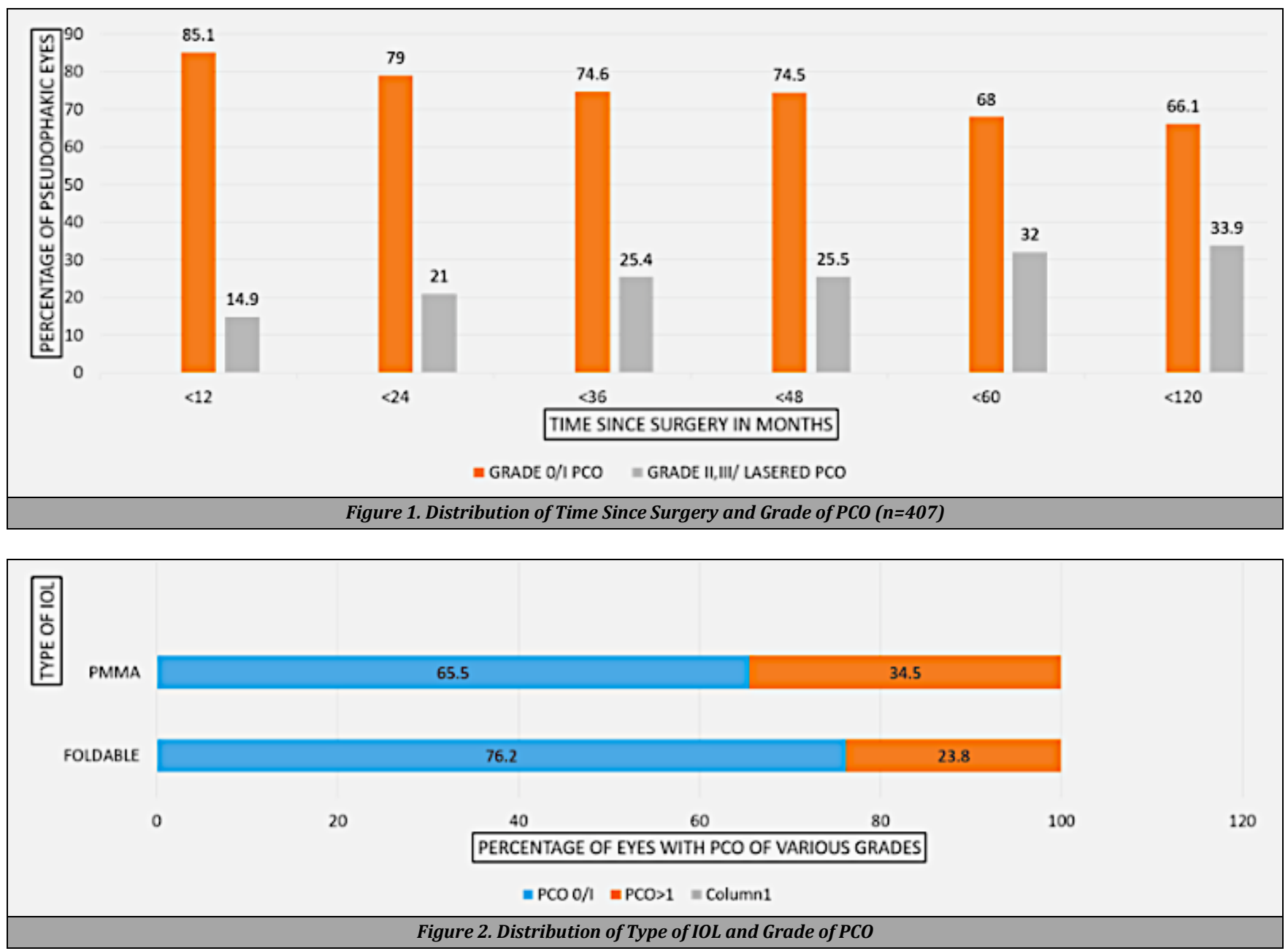

\section{Factors Affecting Development of PCO}

(a) Age - Mean age of study population was $68.1+8.3$ years (range 14-86 years). The range of prevalence of PCO $>$ Grade I for all other age groups was $21.4-36.1 \%$. Being minimum (21.4\%) in age group 55-59 years and maximum (36.1\%) in age group 75-79 years (Table No. 10). Thus, no statistically significant correlation could be established between age and prevalence of PCO $(\chi 2=1.09, \mathrm{p}>0.05$ in hospital group and $\chi 2=9.09, p>0.05$ in survey group). Josef et al (2002) in a 3 Year Retrospective Study on 1440 Patients Operated for Cataract Reported a Higher Frequency of PCO in age group 60-70 years. This could be because of confounding variable of increasing duration since surgery with increasing age. ${ }^{9}$ Mian (2005) compared the Nd-YAG capsulotomy rates in a study on 434 eyes of 329 patients who had cataract extraction and IOL implantation and reported that there was no difference in $\mathrm{Nd}$ YAG capsulotomy rates when comparing age. ${ }^{10}$

(b) Sex - In the study, 33.4\% eyes of male persons and $34.6 \%$ eyes of female persons developed PCO $(\chi 2=0.67, \mathrm{p}>0.05)$. No statistically significant difference was noted in rates of PCO among the two sexes in both the groups of patients. This is consistent with the results in literature. ${ }^{10}$

(c) Time Since Surgery - Mean duration since surgery among total 407 pseudophakic eyes included in the study was $27.9+$ 23.7 months (range 1-120 months), 14.9\% eyes developed visually significant PCO in $<12$ months since surgery. Prevalence of PCO ranged from $14.9 \%$ in $<12$ months since surgery to $32.0 \%$ at $<60$ months since surgery $(\chi 2=23.99$, $\mathrm{p}<0.05)$. Thus, increasing time since surgery was associated with statistically higher PCO rates $(\chi 2=23.99, \mathrm{p}<0.05)$. Various studies with similar results have been reported in the literature..$^{1,2,8}$

(d) Type of Surgery - Among hospital group of 407 pseudophakic eyes, 57 (51.8\%) of the eyes operated by Conventional ECCE + IOL developed PCO compared to 81 (27.3\%) of eyes operated by SICS / PHACO + IOL developing PCO. Thus, there was lesser prevalence of significant PCO in the eyes operated by SICS / PHACO + IOL technique, which was statistically significant $(\chi 2=21.58, \mathrm{p}<0.05)$. This is related to differences in various surgery related factors i.e. extensive cortical clean up, polishing of capsule and capsulorrhexis on IOL edge etc. in these two different surgical techniques as reported in various studies. ${ }^{11}$

(e) Type of IOL - In the study group which included 5 (23.9\%) of the eyes with a Foldable IOL developed PCO as compared to 133 (34.5\%) in the eyes implanted with a PMMA IOL. Prevalence of PCO were higher in PMMA IOL as is reported in the Literature also, $12,2,13,14,15,16$ but the results in the present study group is not significant statistically $(p>0.05)$ probably on account of sample characteristics where number of foldable IOLs is too less (this being a rural cohort, mostly receiving a cataract surgery in a camp setting) to compare. 
(f) Position of IOL - In the study group, 45 (59.2\%) of the eyes with a Decentered IOL had PCO as compared to 93 (28.1\%) of eyes within the Bag placed IOL group. There was higher prevalence of visually significant PCO in eyes with decentered IOL, as compared to eyes within the Bag IOL placement. These results are statistically $\left(\chi^{2}=26.71, \mathrm{DF}=1, \mathrm{p}=0.00000\right)$. These findings are similar to the ones in several studies. ${ }^{17,18}$

(g) Diabetes - Out of 407 pseudophakic eyes included in the study, history of diabetes was noted in 14 persons, of whom 14 (3.4\%) pseudophakic eyes were included in this study and 9 (64.3\%) of these developed PCO. Prevalence of PCO among eyes of non-diabetics was 129 (32.8\%) (Table No. 13). The prevalence of PCO was significantly higher among diabetic people $\left(\chi^{2}=4.65, \mathrm{p}<0.05\right)$. Various studies quote different results on risk of development of PCO in diabetes with some reporting no risk of PCO among Diabetics, ${ }^{3}$ while the others reporting lower long term incidence of PCO in diabetics. ${ }^{19}$ The differences in various studies could be attributable to multifactorial causation of PCO giving rise to other variables as confounding while comparing a single factor.

(h) Uveitis - In our group of patients 86 (46.7\%) of the eyes with uveitis had PCO whereas 52 (23.3\%) of the operated eyes with no evidence of uveitis developed PCO. The presence of uveitis in pseudophakic eyes, was significantly related to higher PCO rates as compared to pseudophakic eyes without uveitis. $\left(\chi^{2}=24.68, D F=1, p=0.000001\right)$ which is consistent with the literature. ${ }^{20,21}$

\section{CONCLUSIONS}

Posterior Capsular Opacification was noted as the commonest cause of blindness and visual impairment in pseudophakic eyes with prevalence of visually significant PCO being $31.4 \%$ of all pseudophakic eyes in the hospital study which obviates the need for Nd-YAG Laser posterior capsulotomy. Multiple factors including time since surgery, type of surgery, position of IOL, diabetes and uveitis were associated with higher prevalence of visually significant PCO. Use of better surgical techniques and superior IOL design remains the key to prevent development of PCO.

Financial or Other Competing Interests: None.

\section{REFERENCES}

[1] Schaumberg DA, Dana MR, Christen WG, et al. A systematic overview of the incidence of posterior capsule opacification. Ophthalmology 1998; 105(7):1213-21.

[2] Apple DJ. Influence of intraocular lens material and design on postoperative intracapsular cellular reactivity. Trans Am Ophthalmol Soc 2000; 98:257-83.

[3] Zaczek A, Zetterstrom C. Posterior capsule opacification after phacoemulsification in patients with diabetes mellitus. J Cataract Refract Surg 1999; 25(2):233-7.
[4] Aslam TM, Dhillon B, Werghi N, et al. Systems of analysis of posterior capsule opacification. Br J Ophthalmol 2002; 86(10):1181-6.

[5] Sundelin K, Sjostrand J. Posterior capsule opacification 5 years after extracapsular cataract extraction. J Cataract Refract Surg 1999; 25(2):246-50.

[6] Zhao J, Sui R, Jia L, et al. Visual acuity and quality of life outcomes in patients with cataract in Shunyi County, China. Am J Ophthalmol 1998; 126(4):515-23.

[7] Dandona L, Dandona R, Naduvilath TJ, et al. Populationbased assessment of the outcome of cataract surgery in an urban population in southern India. Am J Ophthalmol 1999; 127(6):650-8.

[8] Prajna NV, Chandrakanth KS, Kim R, et al. The Madurai intraocular lens study II: clinical outcomes. Am J Ophthalmol 1998; 125(1):14-25.

[9] Schmidbauer JM, Vargas LG, Apple DJ, et al. Evaluation of neodymium:yttrium-aluminum-garnet capsulotomies in eyes implanted with AcrySof intraocular lenses. Ophthalmology 2002; 109(8):1421-6.

[10] Mian SI, Fahim K, Marcovitch A, et al. Nd:YAG capsulotomy rates after use of the AcrySof acrylic three piece and one piece intraocular lenses. $\mathrm{Br} \mathrm{J}$ Ophthalmol 2005; 89(11):1453-7.

[11] Pandey SK, Apple DJ, Werner L, et al. Posterior capsule opacification: a review of the aetiopathogenesis, experimental and clinical studies and factors for prevention. Indian J Ophthalmol 2004; 52(2):99-112.

[12] Coombes A, Seward H. Posterior capsular opacification prevention: IOL design and material. Br J Ophthalmol 1999; 83(6):640-1.

[13] Hollick EJ, Spalton DJ, Ursell PG, et al. Posterior capsular opacification with hydrogel, polymethylmethacrylate, and silicone intraocular lenses: two-year results of a randomized prospective trial. Am J Ophthalmol 2000; 129(5):577-84.

[14] Wejde G, Kugelberg M, Zetterstrom C. Posterior capsule opacification: comparison of 3 intraocular lenses of different materials and design. J Cataract Refract Surg 2003; 29(8):1556-9.

[15] Hayashi H, Hayashi K, Nakao F, et al. Quantitative comparison of posterior capsule opacification after polymethylmethacrylate, silicone, and soft acrylic intraocular lens implantation. Arch Ophthalmol 1998; 116(12):1579-82.

[16] Li N, Chen X, Zhang J, et al. Effect of AcrySof versus silicone or polymethyl methacrylate intraocular lens on posterior capsule opacification. Ophthalmology 2008; 115(5):8308.

[17] Schmidbauer JM, Escobar-Gomez M, Apple DJ, et al. Effect of haptic angulation on posterior capsule opacification in modern foldable lenses with a square, truncated optic edge. J Cataract Refract Surg 2002; 28(7):1251-5.

[18] Tognetto D, Sanguinetti G, Cernobori R, et al. Intraocular lens decentration and posterior capsule opacification: anatomo-pathologic findings after implantation of AMOSI40 IOLS. Eur J Ophthalmol 2006; 16(1):46-51.

[19] Elgohary MA, McCluskey PJ, Towler HMA, et al. Outcome of phacoemulsification in patients with uveitis. $\mathrm{Br} \mathrm{J}$ Ophthalmol 2007; 91(7):916-21. 
[20] Magno BV, Datiles MB, Lasa MS, et al. Evaluation of visual function following neodymium: YAG laser posterior capsulotomy. Ophthalmology 1997; 104(8):1287-93.
[21] Pahor D, Gracner B, Gracner T, et al. Posterior capsule opacification after phacoemulsification in patients with rheumatoid arthritis. Wien Klin Wochenschr 2006; 118 Suppl 2:38-42. 